\title{
Growth of Bone
}

\section{By R. Walmsley, Department of Anatomy, United College, University of St Andrews}

The plasticity of bone is generally recognized and bone is sometimes given the credit of being second only to blood in this quality. During growth its plasticity is especially apparent.

The ossified diaphysis of a humerus of a 5 -month-old foetus is a tiny miniature of the adult, with a bony diaphysis of about $35 \mathrm{~mm}$, a girth at the middle of less than $3 \mathrm{~mm}$ and cartilaginous ends. This foetal bone, when placed within the medullary cavity of the adult bone, is almost lost, but if its life and growth had continued, it would have created within itself a medullary cavity many times its own original size and formed a shaft and ends that would have retained the same essential form throughout its foetal months and postnatal years (Pl. I, I).

The cartilaginous precursor of a long bone early assumes a form that embodies the main features of the adult bone and so each has its individuality stamped on it. In any consideration of bone growth this early assumption of adult form and its retention throughout the period of growth must be borne in mind and the problems pertaining to bone growth can never be dissociated from this conservation of shape.

Over two hundred years ago Stephen Hales (1727) deduced from a single experiment that bones grow at their ends and not interstitially. Punching two holes half an inch apart in the shaft of the tarso-metatarsal bone of a young chicken, he observed that 2 months later they remained separated by the same distance although the whole bone had grown an additional inch; he furthermore noted that the greater part of the growth had occurred at the upper end of the bone. The account of these observations is preceded by a reference to the growth of cartilage which he describes as the non-ossified 'tender ductile bone of young animals'. Growth in this tissue he postulates as occurring in every part, and this may justifiably be interpreted in our terminology of to-day as interstitial growth. Adequate credit should always be given to the observations of Hales on both cartilage and bone as they are the first record of the manner in which cartilage grows in size and long bones grow in length, and the truth of them has been upheld by the many others who have investigated this problem; the fact that one experiment only was conducted should not detract from the value of Hales's accurate observations and deductions. The celebrated researches of Duhamel (1743) and Hunter ( 1837 ) on the growth of long bones in part at least constituted an elaboration of Hales's earlier work, but they carried the problem a stage further by their inquiries into the growth in girth of long bone. John Hunter, in his investigation of this phenomenon, utilized an observation that had been recorded by John Belchier in $173^{6}$, namely that pigs fed with a diet containing an infusion of madder root had certain parts of their bones coloured red. Hunter demonstrated that the portion of bone stained by the madder root was restricted to that portion of the bone laid down during the feeding of the dye, the remaining part retaining a normal bone colour. By continuous and intermittent feeding of the dye, Hunter conclusively proved that bones 
grow in girth by the deposition of new bone on the surface, and that the simultaneous widening of the marrow cavity occurs by the absorption of the bone lining it. Hunter also directed his attention to the growth that occurs in the neck of the femur, a part of the diaphysis, and observed that during growth there is an accretion of bone on its upper aspect and an absorption of bone from the lower so that the form of the neck is retained. Brash $(1934 a, b)$ in his meticulous studies on the bones of madder-fed pigs has analyzed the growth of some of the skull bones and of the mandible and his observations have proved without doubt that bone growth and bone absorption are solely surface phenomena. The definitive form assumed by any bone is therefore determined by the synchronous deposition and absorption of bone, and any major upset in the balance of these normally harmonious processes will in turn reflect itself in a departure from normal in the form of a bone.

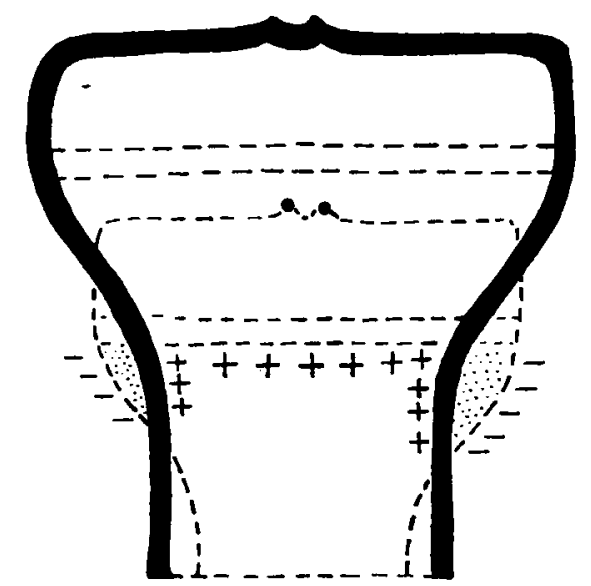

Fig. x. Schematic diagram of the growing end of a long bone to illustrate the modelling resorption on the outer surface of diaphysis (indicated by minus sign) and the deposition of bone on the endosteal surface (indicated by plus sign). The absorbed bone has been stippled. The region of the diaphysis, at which growth in length takes place, is also indicated by plus signs.

Lacroix (195I) and Leblond, Wilkinson, Bélanger \& Robichon (1950) have drawn especial attention to the modelling of bone that occurs in the diaphysis adjacent to the epiphysis, and the latter workers, who used radio-phosphorus ${ }^{32} \mathrm{P}$ in their investigations, have stressed that the ossification that occurs in this region is endosteal in type; they have, moreover, emphasized that their conclusions are in complete accord with the observations of Kölliker ( 1873 ). (See Fig. I.)

No account of growth of bone, however abbreviated, can fail to include reference to the observations of Harris (I933) on the lines of arrested growth that may be seen by radiography in the bones of young people who have suffered from acute illness. These lines, which are semi-permanent, appear at both ends of the diaphysis and as long as they persist they remain the same distance from each other throughout the growth of the bone, although they recede at unequal rates from the ends. This feature of the lines of arrested growth is to be regarded as additional proof that growth in length of a bone occurs only at the ends and not interstitially.

In this attempt to summarize the mode of growth in girth of a bone it has been stated 
that this process is essentially a surface phenomenon, and by this it is implied that new bone is always laid down on the surface of old bone. It is at this stage that I should like to extend this conception of growth to the growing ends of bone as in these situations new bone is formed on the surface of cartilaginous remnants or on bone already formed so that the process there again is truly a surface phenomenon. As the conception of surface growth in these situations is perhaps more difficult to appreciate, the term of appositional growth as favoured by Weinmann \& Sicher (1947) is perhaps preferable. All bone growth, whether in relation to growth in girth or growth in length, is therefore regarded as appositional growth, and this concept is in accord with all known facts.

A necessary prerequisite to an appreciation of bone growth is a familiarity with the early stages of ossification, and in those bones that are preformed in cartilage this in turn hinges on a knowledge of the formation of their cartilaginous forerunners. The consideration of the early stages of chondrification of the humerus and its subsequent ossification formed one of the last works of that master of embryology, George L. Streeter (I949). In the $5 \mathrm{~mm}$ human embryo the limb buds are established as outgrowths from the non-segmented part of the body wall and each is first represented by a surface layer of ectoderm, and an undifferentiated mass of mesenchyme; evidence of the skeletal condensation can be well seen in the $12 \mathrm{~mm}$ embryo. Thereafter the cartilaginous model rapidly assumes the general form of the bone which is to replace it, and the determination of this form must lie in the chondroblasts that lie in the deeper layer of the perichondrium. It is the multiplication and growth of the chondroblasts and the formation of intercellular substance that determine the shape of these primary skeletal elements.

The changes that occur in the oldest cartilage cells in the central region of the cartilaginous model are well known, and it need only be stressed that one can trace successive phases of younger cells as one passes to the ends of the cartilaginous model (Pl. I, 2).

Bloom \& Bloom (1940), in their consideration of the calcification of developing bone, have shown that calcification of the cartilage always precedes its vascularization. At this time the cartilage matrix in the middle of the shaft is represented by thin laminae between the lacunae that lodge the degenerating cells and it is in these laminae that the calcification occurs (Pl. I, 3). Simultaneously with the calcification of the cartilage a perichondrial collar of bone is formed around the central part of the shaft so that the first ossification that occurs in a cartilaginous bone is of the membranous type (Pl. I, 4). This collar of bone, as stated by Streeter (1949), is a continuous collar and does not in the first instance show the vascular foramina that are such a prominent feature of it at a slightly later date.

The inductive influence of the central cartilaginous cells in the formation of the perichondrial osseous collar has been fully presented and discussed by Lacroix (1951), and Streeter (1949) suggests that the stage of degeneration which these cells attain is the apotheosis of their development.

The entirety of the osseous collar is soon disturbed by the appearance in it of lacunae through which osteoblasts stream and blood vessels pass. The breakdown of 
the cartilage is thereafter relatively great and it is on spicule-like remnants of it that endochondral ossification occurs ( $\mathrm{Pl} .1,4,5)$. These cartilaginous remnants are gradually replaced by bone or disappear without replacement, and as the ossific process extends towards the ends of the cartilage and the bone gains in width by subperiosteal growth, the earliest formed bone is absorbed and the medullary cavity thereby increased in size. It is not appropriate for me to enter into a discussion of the part played by the osteoblast or the osteoclast, but the microscopical studies of Kölliker (1873) on the last-named cell have frequently been substantiated by other workers, and the sites of its presence have been repeatedly verified as the sites of bone absorption. (See also, Leriche \& Policard, I928; Arey, I920; Dodds, 1932; Leblond et al. 1950 ).

In many long bones an epiphyseal centre or centres of ossification appear within the cartilage at both ends, and these differ from the diaphyseal process of ossification in being entirely endochondral. It is generally recognized that the advent of ossification in the cartilaginous ends bears no relationship to the volume of the cartilage, as a welldeveloped system of vascular canals is clearly demonstrable in the cartilage ends of all the larger long bones before ossification (Pl. 2, 5). The character of these canals has been fully discussed by Haines (r933) and Hurrell (r934).

In man the secondary centres of ossification appear throughout the first 15 years of life, and though the time of appearance of any one particular centre may differ in different individuals over a period of several years, the sequence of appearance of secondary centres is remarkably constant. The time of the appearance of a secondary ossific centre bears some relationship to its time of fusion and in any one bone the centre that appears first usually fuses last (P1. 2, I-4). For this reason a long bone has usually one end which contributes more to the length than the other, but this depends less on the longer life of the epiphyseal or growth cartilage at the growing end than on the greater activity of the cartilage at that end (see Payton, 1933; Harris, 193 $a, b$; Gill \& Abbott, 1942). In the humerus, for example, about $80 \%$ of the total elongation is estimated as occurring at the upper growth cartilage (Bisgard \& Bisgard, 1935), and in the observations that $I$ have made of the vertebrae of various mammals $I$ have been able to correlate the greater activity and the longer life of the growth cartilage that separates the caudal epiphysis from the vertebral body.

The definitive form of bones is regarded as dependent partly on the growth pattern inherent in the bones themselves and partly on the extrinsic forces to which they are subjected throughout life. Murray (1936) has presented a most admirable survey of his own investigations and those of others on experimental work in embryos that has proved the self-differentiating qualities of limb bones. The report of Murray \& Huxley (1925) on the result of grafting the hind-limb bud of a 4-day chick embryo on the chorio-allantoic membrane of another chick was a major contribution to the knowledge of bone growth. After 6 days' cultivation the undifferentiated mesenchyme of the bud had formed a recognizable femur with a collar of perichondral bone. The inherent power of differentiation may be demonstrated in the human femur, where a patellar surface develops with the characteristic larger lateral patellar lip that is so essential for the normal retention of the patella in the extended position of the knee joint; this 
asymmetrical development of the patellar surface occurs when the patella is not in contact with it, owing to the extreme flexion of the knee joint. In contra-distinction to this inherent power of self-differentiation, it is of interest to note that the tendon of the popliteus which is so closely related to the lateral femoral condyle throughout foetal life stamps a groove that persists throughout adult life.

In this synopsis of some aspects of bone growth, I have knowingly omitted much that is of paramount importance in the subject, but to do otherwise in the space at my disposal would be quite outside my power.

Arey, L. B. (1920). Amer. F. Anat. 26, 315.

\section{REFERENCES}

Belchier, J. (1736). Philos. Trans. 39, 287.

Bisgard, J. D. \& Bisgard, M. E. (1935). Arch. Surg., Chicago, 31, 568.

Bloom, W. \& Bloom, M. A. (1940). Anat. Rec. 78, 497.

Brash, J. C. (1934a). Edinb. med. F. 41, 305.

Brash, J. C. (1934b). Edinb. med. F. 41, 363.

Dodds, G. S. (1932). Amer. F. Anat. 50, 97.

Duhamel, H. L. (1743). MÉm. Acad. R. Belg. 56, III.

Gill, G. G. \& Abbott, L. C. (1942). Arch. Surg., Chicago, 45, 286.

Haines, R. W. (1933). F. Anat., Lond., 68, 45.

Hales, S. ( 1727$)$. Vegetable Statics. London: Robinson and Roberts.

Harris, H. A. (1931 a). Brit. F. Radiol. 4, 561.

Harris, H. A. (1931 b). Brit. F. Radiol. 4, 622 .

Harris, H. A. (1933). Bone Growth in Health and Disease. London: Oxford University Press.

Hunter, J. (1837). Works, Palmer's edition. London : Longman, Ress, Orme, Brown, Green and Longman. Hurrell, D. J. (1934). F. Anat., Lond., 69, 47.

Kölliker, A. (1873). Die Normale Resorption des Knochengewebes und ihre Bedeutung für die Entstehung der Typischen Knochenformen. Leipzig: Vogel.

Lacroix, P. (1951). The Organization of Bones. London: J. and A. Churchill.

Leblond, C. P., Wilkinson, G. W., Bélanger, L. F. \& Robichon, J. (1950). Amer. F. Anat. 86, 289.

Leriche, R. \& Policard, A. (1928). The Normal and Pathological Physiology of Bone. London: Henry Kimpton.

Murray, P. D. F. (1936). Bones. Cambridge: University Press.

Murray, P. D. F. \& Huxley, J. S. (1925). F. Anat., Lond., 59, 379.

Payton, C. G. (1933). Э. Anat., Lond., 66, 414.

Streeter, G. L. (1949). Contr. Embryol. Carneg. Instn, 33, I49.

Weinmann, J. P. \& Sicher, H. (1947). Bone and Bones. London: Henry Kimpton.

\section{EXPLANATION OF PLATES}

\section{Plate I}

1. Photograph of section of the adult human humerus in the medullary cavity of which lies the diaphysis of a 5-month foetal humerus. About $80 \%$ of growth in length of the humerus occurs at the upper epiphyseal cartilage, hence the foetal humerus has been placed near the lower end of the adult bone. $\times t$.

2. Longitudinal section of human foetal phalanx showing degeneration of cartilage cells in mid-zone before formation of bone. $\times 68$.

3. Section of human foetal phalanx showing further stage of degeneration of cartilage cells in midzone. Lacunae containing cells are separated from one another by thin calcified laminae. Perichondrial collar of bone surrounds degenerating cells and is seen as dark band between cartilage and perichondrium. $\times 56$.

4. Section of human foetal phalanx after appearance of primitive medullary cavity. Periosteal collar of bone is now clearly evident and mid-zone of cartilage has been absorbed. $\times 17$.

5. Mid-zone of same phalanx as in 4, showing vessel piercing periosteal collar of bone: bone is also being laid down on remnants of calcified cartilage. (The bone is more darkly stained than cartilage.) $\times 87$.

\section{Plate 2}

1. Sagittal section of intervertebral disk and parts of adjacent vertebrae of young rabbit. The epiphyseal (or growth) cartilage is seen separating the diaphysis of the vertebral body from the epiphysis in both the upper and lower vertebrae. Most of the growth in length of a vertebra occurs at its lower end and therefore the epiphyseal cartilage in the upper vertebra is more active than that in the lower. $\times 12$. 


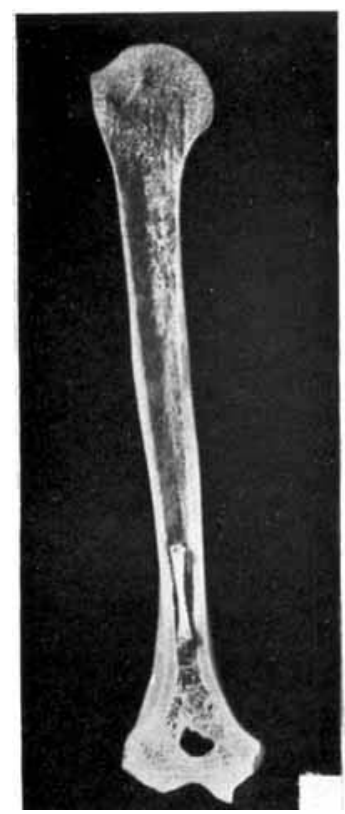

1

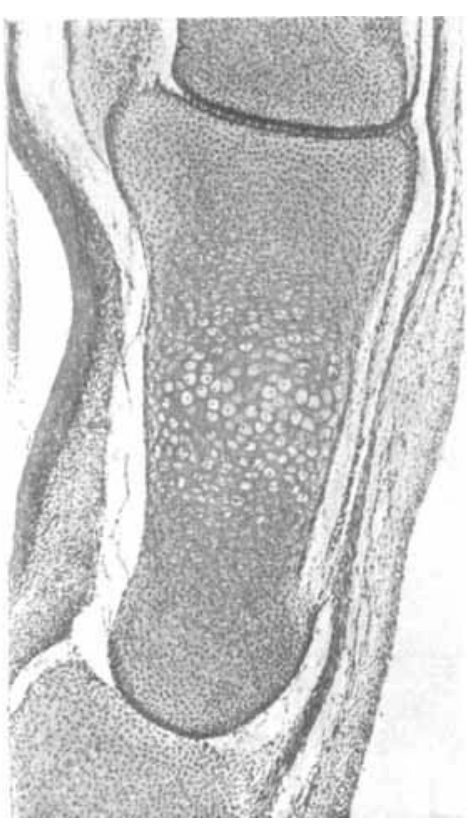

2

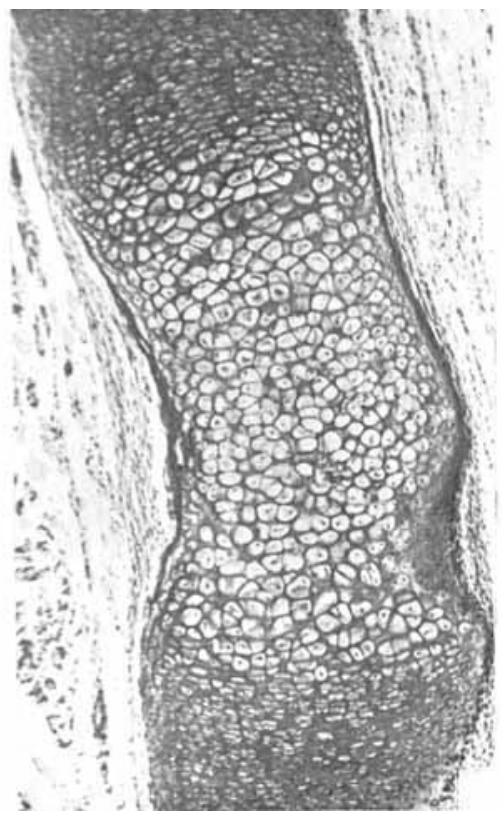

3

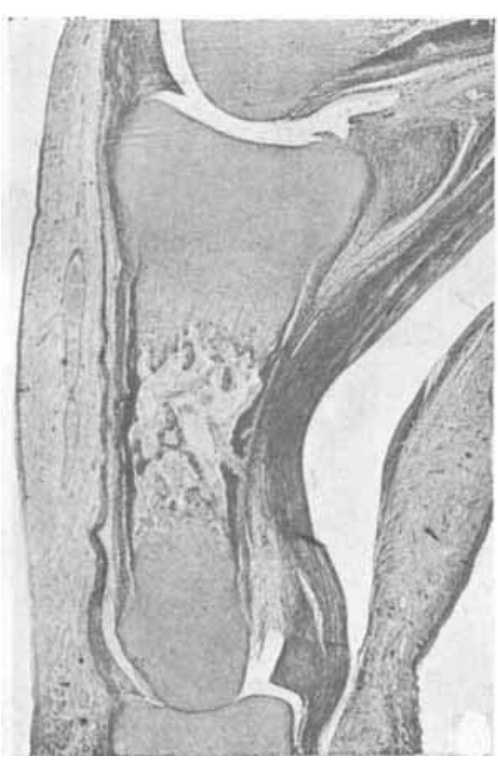

4

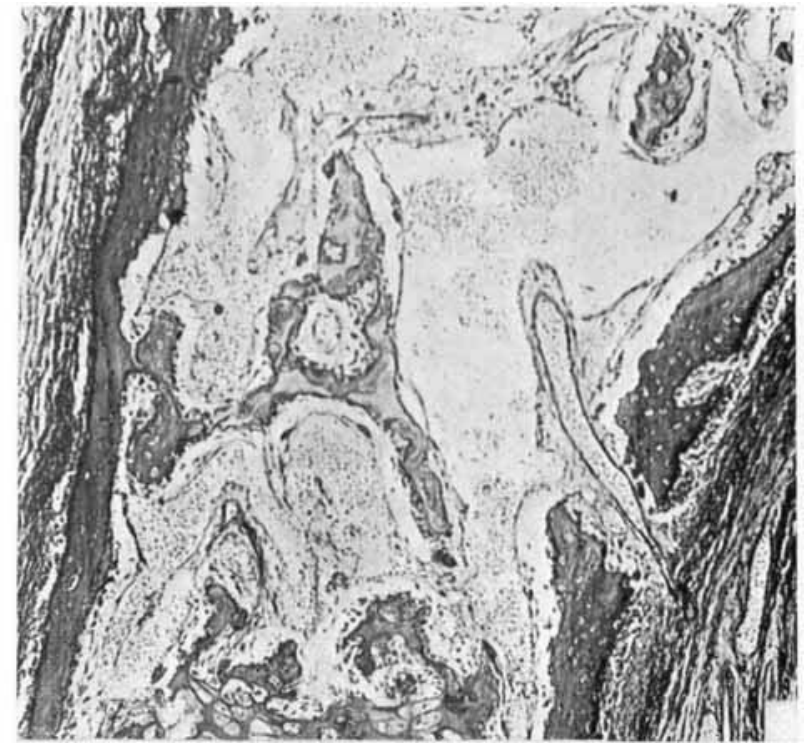

5

British Fournal of Nutrition, Vol. 6, No. 4 


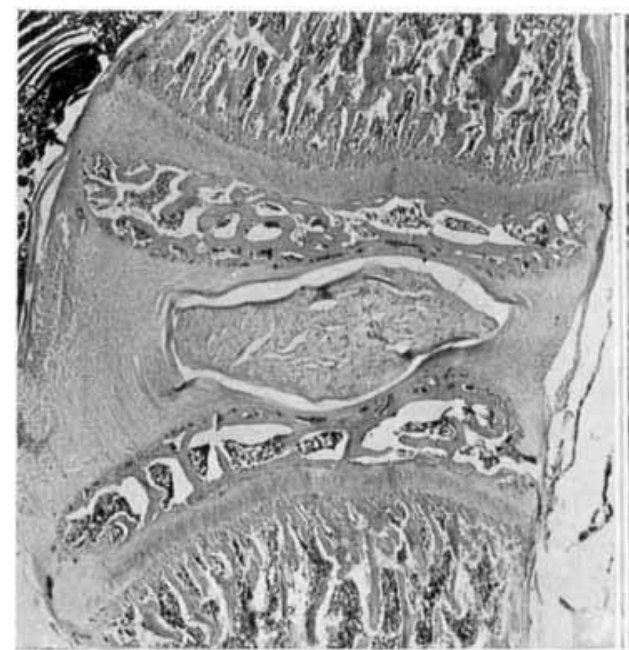

1

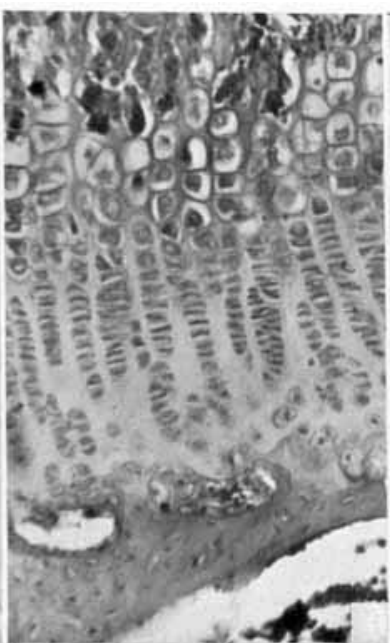

2

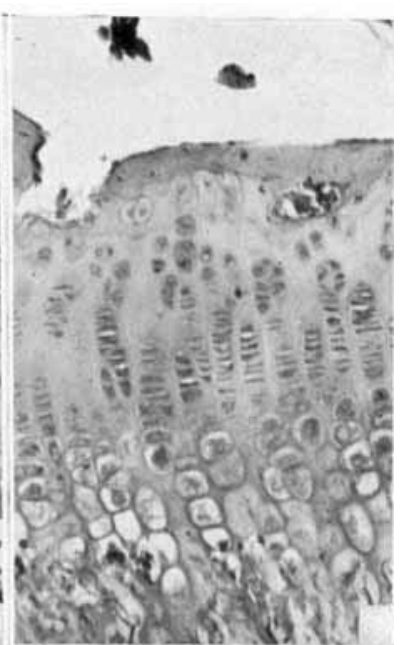

3

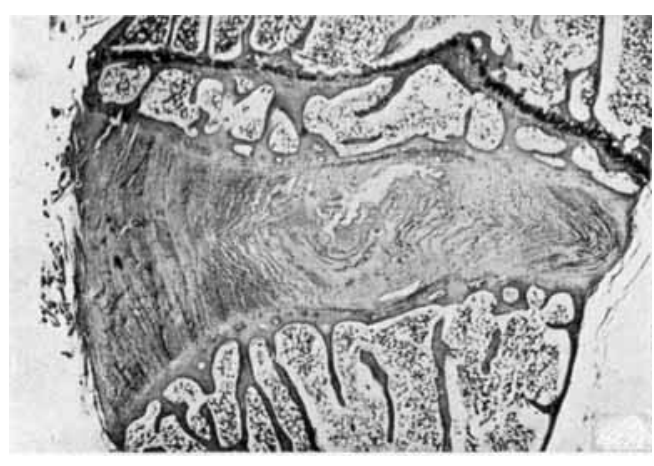

4

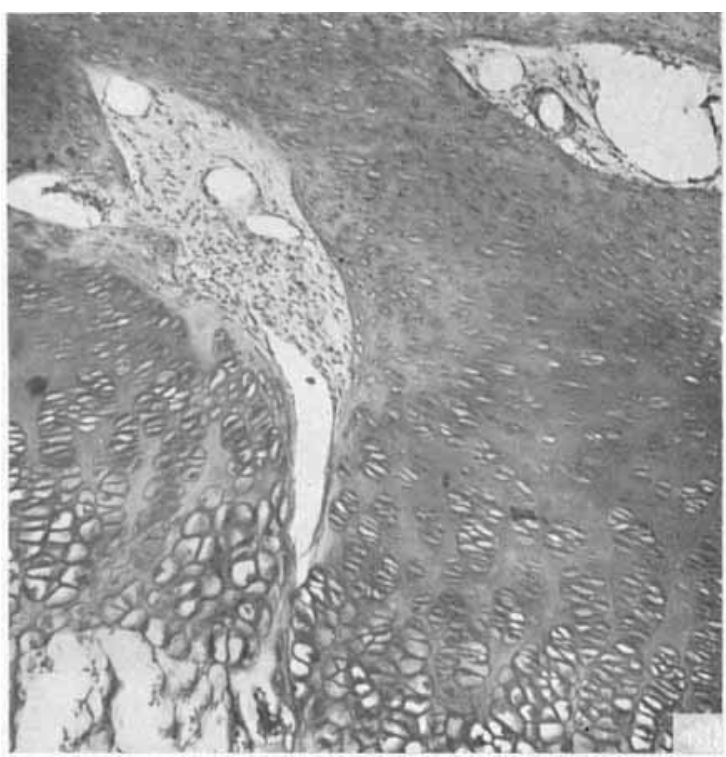

5

British Fournal of Nutrition, Vol. 6, No. 4 
2. Part of epiphyseal cartilage of upper vertebra shown in I. Long columns of cartilage cells, indicating the intense activity of the cartilage, are evident. $\times 130$.

3. Part of epiphyseal cartilage of lower vertebra shown in 1 . Cartilage columns are shorter than those in 2 , indicating less marked activity of the growth cartilage. $\times 130$.

4. Sagittal section of lumbar vertebrae of mature rabbit showing persistence of epiphyseal cartilage in upper vertebra. This figure demonstrates that the more active epiphyseal cartilage in a bone tends to persist longer. The lower end of a vertebral body in most pronogrades is the 'growing' end. $\times$ Io.

5. Section of upper end of femur of newborn child. The ends of most long bones before ossification are nourished by vessels running in cartilage canals. Some of the vessels pass from the diaphysis into the cartilaginous end and an example of this is seen in this figure. The cartilage is in the upper part of the figure and the diaphysis of the bone towards the lower part. $\times 86$.

\section{Bone as a Mineral Reserve}

\section{By E. C. Owen, The Hannah Dairy Research Institute, Kirkhill, Ayr}

Bone gives its possessor biochemical as well as structural advantages. Bone is not a dead tissue and the calcium and phosphorus which give it its hardness are also labile, if need be as a source of nourishment for the softer more actively metabolizing tissues of the body. Ca deficiency in wild animals should be a rare phenomenon. P, however, is much harder to come by. Fishes living on the continental shelves of the various land masses acquire $\mathbf{P}$ by eating small arthropods and algae. The small plants and animals of the phyto- and zoöplankton keep the phosphate wastes from the land masses in biological circulation. The fate of $\mathrm{P}$ has, in the past, been to pass from the fish to the birds which prey on them and so to be deposited on oceanic islands as guano. Rock phosphate deposits, on which modern agriculture, and therefore human nutrition, largely depend, are chiefly fossilized guano. Two very large deposits of apatite, one in the Kola Peninsula, the other in Canada, are exceptions in being igneous in origin. As every farmer knows $\mathrm{P}$ is dearer than he would like it to be. $\mathrm{Ca}$, on the other hand, is literally 'dirt cheap'. It is perhaps therefore not surprising that $\mathrm{P}$ deficiency is still a hazard of both plant growth and animal production.

It is a fact of history that all the newer countries had difficulty in raising cattle. The reason was a mystery until Theiler (1919) (cf. Theiler \& Green, I93 I-2) working in South Africa, showed that the difficulty was due to aphosphorosis. This discovery, together with similar work elsewhere in the world, gave the needed impetus to the superphosphate industry which converts rock phosphate to a form more readily available to plant roots. Nevertheless, for human and farm animal alike, aphosphorosis is still an ever-present hazard. However, if children can get plenty of milk, there is little need to worry about their intake either of $\mathrm{Ca}$ or of P. Drinking half a pint of cow's milk per day makes an adult safe from aphosphorosis. An expectant or nursing mother ought to have twice as much. Herring, if well cooked, provide not only both $\mathrm{Ca}$ and $\mathrm{P}$ in the bones, which one eats, but also vitamin $\mathrm{D}$ in the body oil. Though it is to be admitted that low-Ca rickets certainly exists (Skill \& Kay, I934), we still do not know if rickets in children and its counterpart, osteomalacia, in later life are primarily due to a deficiency in $\mathrm{Ca}$ or in $\mathrm{P}$. From animal experiments, such 